\title{
Avaliação dos parâmetros químicos de qualidade da água em um ecossistema aquático lótico
}

Evaluation of water quality chemical parameters in a lotic aquatic ecosystem

Evaluación de los parámetros químicos de la calidad del agua en un ecosistema acuático lotico

João Miguel Merces Bega

Mestrando em Recursos Hídricos e Tecnologias Ambientais, bolsista CNPq, FEIS-UNESP joaomiguelbega@gmail.com

Natasha Ulhiana Ferreira Ribeiro Mestranda em Recursos Hídricos e Tecnologias Ambientais, bolsista CAPES, FEIS-UNESP natasha_ul@yahoo.com.br

Juliana Cristina Ribeiro Almeida Mestranda em Recursos Hídricos e Tecnologias Ambientais, bolsista CAPES, FEIS-UNESP juliana-almeida15@hotmail.com

Amanda de Moraes Ricardi Mestranda em Recursos Hídricos e Tecnologias Ambientais, bolsista CNPq, FEIS-UNESP amandademricardi@gmail.com

Jefferson Nascimento de Oliveira Professor Doutor, FEIS-UNESP jefferson.nascimento@unesp.br 


\title{
RESUMO
}

Os ecossistemas aquáticos em ambientes urbanos se encontram, em grande parte, degradados. Além disso, o ser humano tem se tornado cada vez mais exigente, aumentando assim o consumo da água para suas distintas atividades. Neste cenário de crescimento da demanda e diminuição da qualidade, evidencia-se a importância do monitoramento ambiental dos recursos hídricos e da existência de técnicas de tratamento das águas superficiais. Este trabalho avaliou um córrego inserido em uma sub-bacia de drenagem altamente urbana. Com o intuito de evidenciar a degradação ambiental nesses ambientes, parâmetros químicos de qualidade da água foram quantificados. Obtiveram-se elevadas concentrações de demanda bioquímica de oxigênio (DBO), nitrogênio total (NT) e fósforo total ( FT), correspondentes, em um dos pontos de interesse, a 267,56;3,35 e $37,00 \mathrm{mg}$. $\mathrm{L}^{-1}$, respectivamente. Como causas principais deste estado encontrado citam-se a falta de preservação no entorno do curso d'água e possíveis ligações ilegais da rede de esgotamento sanitário com a rede de drenagem pluvial. Por fim, comenta-se que embora tenha sido considerado um curso de Classe 2, claramente, pelos valores encontrados, o córrego avaliado se enquadra melhor na Classe 3 ou 4 , elucidando o que vem sendo verificado na maioria das cidades brasileiras.

PALAVRAS-CHAVE: Poluição difusa. Ligações clandestinas. Crise Hídrica.

\begin{abstract}
Aquatic ecosystems in urban environments are largely degraded. In addition, the human being has become increasingly demanding, thus increasing the consumption of water for their different activities. In this scenario of growing demand and decreasing quality, the importance of environmental monitoring of water resources and the existence of surface water treatment techniques are evident. This work evaluated a stream inserted into a highly urban drainage sub-basin. In order to evidence the environmental degradation in these environments, chemical parameters of water quality were quantified. High concentrations of biochemical oxygen demand (BOD), total nitrogen (TN) and total phosphorus (TP) were obtained, corresponding in one of the points of interest to $267.56 ; 3.35$ and $37.00 \mathrm{mg} . \mathrm{L}^{-1}$, respectively. The main causes of this state are the lack of preservation around the watercourse and possible illegal connections of the sewage system to the rainwater drainage network. Finally, it is commented that although it was considered a Class 2 course, clearly, by the values found, the stream evaluated fits best in Class 3 or 4, elucidating what has been verified in most Brazilian cities.
\end{abstract}

KEYWORDS: Diffuse pollution. Clandestine connections. Water crisis.

\section{RESUMEN}

Los ecosistemas acuáticos en entornos urbanos están en gran medida degradados. Además, el ser humano se ha vuelto cada vez más exigente, aumentando así el consumo de agua para sus diferentes actividades. En este escenario de demanda creciente y calidad decreciente, la importancia del monitoreo ambiental de los recursos hídricos y la existencia de técnicas de tratamiento de aguas superficiales son evidentes. Este trabajo evaluó una corriente insertada en una subcuenca de drenaje altamente urbana. Para evidenciar la degradación ambiental en estos ambientes, se cuantificaron los parámetros químicos de la calidad del agua. Se obtuvieron altas concentraciones de demanda bioquímica de oxígeno (DBO), nitrógeno total (NT) y fósforo total (FT), correspondientes en uno de los puntos de interés a 267.56; 3.35 y $37.00 \mathrm{mg} . \mathrm{L}^{-1}$, respectivamente. Las principales causas de este estado son la falta de preservación alrededor del curso de agua y las posibles conexiones ilegales del sistema de alcantarillado a la red de drenaje de aguas pluviales. Finalmente, se comenta que aunque se consideró un curso de Clase 2, claramente, por los valores encontrados, el flujo evaluado encaja mejor en Clase 3 o 4, aclarando lo que se ha verificado en la mayoría de las ciudades brasileñas.

PALABRAS CLAVE: Contaminación difusa. Conexiones clandestinas. Crisis de agua. 


\section{INTRODUÇÃO}

Os recursos hídricos, principalmente os inseridos em meio urbano, têm passado por uma intensa degradação ambiental nessas últimas décadas, decorrente das ações antrópicas desenvolvidas nas bacias de drenagem (MC DONALD et al., 2011; ZAMBRANO, POLETO e OLIVEIRA, 2017; RIGHETTO, GOMES e FREITAS, 2017). O processo de urbanização altera o caminho natural das águas, o que provoca, muitas vezes, um aumento de substâncias carreadas superficialmente, as quais têm como destino final os cursos receptores (MENEZES et al., 2016). Nos centros populacionais, as ruas, sarjetas e telhados são os principais contribuintes de poluentes ao escoamento superficial urbano, resultado do aporte difuso dessas cargas.

A forma de uso e ocupação do solo influencia diretamente na qualidade das águas superficiais e subterrâneas (BU et al., 2014; FIA et al., 2015). Em áreas urbanas, a cobertura associa-se à poluição orgânica, assim como ao aporte de nutrientes e metais (KANG et al., 2010). Do ponto de vista temporal, as oscilações na qualidade da água podem refletir as mudanças no uso da cobertura de uma bacia hidrográfica (KALSCHEUR et al., 2012). Existem muitos estudos que relacionam a mudança antrópica na paisagem com a modificação da integridade biológica do ambiente aquático (MUNYKA, KONGO e KIMWAGA, 2015; BAUMGARTNER e ROBISON, 2017). No que tange ao aumento populacional urbano brasileiro, tem-se verificado, nos últimos anos, um crescimento exponencial de forma descontrolada e caótica, com uma projeção de que até 2050, 93\% da população brasileira esteja vivendo em áreas urbanas (UNITED NATIONS, 2018). Verifica-se, em muitas cidades, que a expansão da malha urbana não segue um planejamento territorial adequado e os órgãos públicos falham em ofertar serviços básicos, como o saneamento. Isto posto, a poluição das águas trata-se de um problema atual, visto que a demanda por água potável dobra a cada 10 anos (SRIVASTAVA, GUPTA e CHANDRA, 2008). Em contrapartida, a matriz aquática se encontra cada vez mais deteriorada, apresentando, frequentemente, resultados de parâmetros que não se enquadram nas normativas restritivas, de acordo com a classe de uso mais exigente (SILVA et al., 2016).

O monitoramento da qualidade da água permite um entendimento dos processos ambientais que ocorrem na bacia hidrográfica, sendo um importante instrumento de sustentação de políticas de gestão de corpos hídricos (GUEDES et al., 2012). Uma avaliação pontual proporciona uma abordagem de conhecimento do recurso avaliado, buscando apresentar o estado qualitativo do ecossistema aquático, com o intuito de subsidiar as ações de controle ambiental e apresentar as localidades mais críticas, que costumam ser objeto de estudo.

Embora haja a existência de inúmeros trabalhos acadêmicos voltados ao tema de acompanhamento ambiental, ainda faltam na literatura contribuições que apresentem os comportamentos e variações de parâmetros indicadores de poluição em cursos d'água inseridos em bacias de drenagem altamente urbanizadas. Assim sendo, buscou-se neste estudo averiguar algumas variáveis químicas em um córrego urbano, de forma a elucidar os fatores responsáveis pela situação encontrada. 


\section{MATERIAIS E MÉTODOS}

\subsection{Caracterização da área de estudo e pontos de amostragem}

O estudo foi realizado no município de Ilha Solteira, localizado no interior do estado de São Paulo, no noroeste paulista, próximo à divisa com o Mato Grosso do Sul. No último senso, a população verificada foi de 25.064 pessoas, com uma estimativa de 26.582 para o ano de 2018 (IBGE, 2012). A cidade conta com uma área territorial de $659 \mathrm{~km}^{2}$, destes, $4,30 \mathrm{~km}^{2}$ são pertencentes a área urbana (PREFEITURA DE ILHA SOLTEIRA, 2018).

Segundo a classificação proposta por Köppen, o clima da região caracteriza-se como tropical semi-úmido, Aw, marcado por chuvas intensas no verão e estiagem no inverno (ALVARES et al., 2013). As temperaturas verificadas ao longo do ano, em sua maioria, se distanciam da média anual, que corresponde a $23,6^{\circ} \mathrm{C}$, e o índice pluviométrico registrado é de $1.300 \mathrm{~mm} / \mathrm{ano}$. $\mathrm{O}$ relevo da região constitui-se, principalmente, por colinas médias e amplas e os tipos de solo frequentemente encontrados são: LV39 (Latossolos Vermelhos) e PVA10 (Argissolos VermelhoAmarelos) (SANTIM, 2010).

O curso d'água analisado, Córrego Sem Nome, tem sua nascente na sub-bacia do Córrego Sem Nome, a qual apresenta uma área de $3,47 \mathrm{~km}^{2}$, correspondendo a $80 \%$ da área urbana do município (SANTIM, 2010). Esse córrego recebe a drenagem, proveniente do escoamento superficial, encaminhada pelas galerias pluviais construídas pela prefeitura. Atualmente, o mesmo se encontra em um estágio avançado de degradação. Por ser um corpo hídrico não enquadrado na classificação dos cursos d'agua em relação ao seu uso mais restritivo, adotou-se a Classe 2 , até que as autoridades outorgantes tenham as devidas informações e o enquadrem em uma categoria.

Os pontos de amostragem foram escolhidos por apresentarem, em uma visita in loco, mau cheiro e reclamações dos cidadãos no entorno do canal de drenagem. Ademais, eles são relativamente distintos quanto à profundidade, largura e velocidade do escoamento. A Tabela 1 apresenta as coordenadas geográficas dos pontos de interesse, enquanto a Figura 1 os mostra dentro da área de estudo. $O$ primeiro ponto amostral (P1) recebe a seu montante a contribuição de uma galeria de água pluvial. Já o segundo ponto amostral (P2) não conta com nenhum aporte específico no trecho entre os dois locais, distantes 250 metros entre si.

Tabela 1: Coordenadas geográficas dos pontos de amostragem

\begin{tabular}{c|c|c}
\hline \multirow{2}{*}{ Pontos amostrais } & \multicolumn{2}{|c}{ Coordenadas } \\
\cline { 2 - 3 } & Latitude & Longitude \\
\hline P1 & $20^{\circ} 25^{\prime} 50.4^{\prime \prime} \mathrm{S}$ & $51^{\circ} 20^{\prime} 06.2^{\prime \prime} \mathrm{W}$ \\
\hline $\mathrm{P} 2$ & $20^{\circ} 25^{\prime} 59.7^{\prime \prime} \mathrm{S}$ & $51^{\circ} 20^{\prime} 06.3^{\prime \prime} \mathrm{W}$ \\
\hline
\end{tabular}

Fonte: Autores. 


\subsection{Análise dos parâmetros}

As coletas foram realizadas no período da manhã (8h00), com as amostras armazenadas para transporte em garrafas de polietileno, seguindo o que está descrito no "Guia nacional de coleta e preservação das amostras - água, sedimentos, comunidades aquáticas e efluentes líquidos" (CETESB, 2011).

Figura 1: Sub-bacia do Córrego Sem Nome e posicionamento dos pontos de amostragem

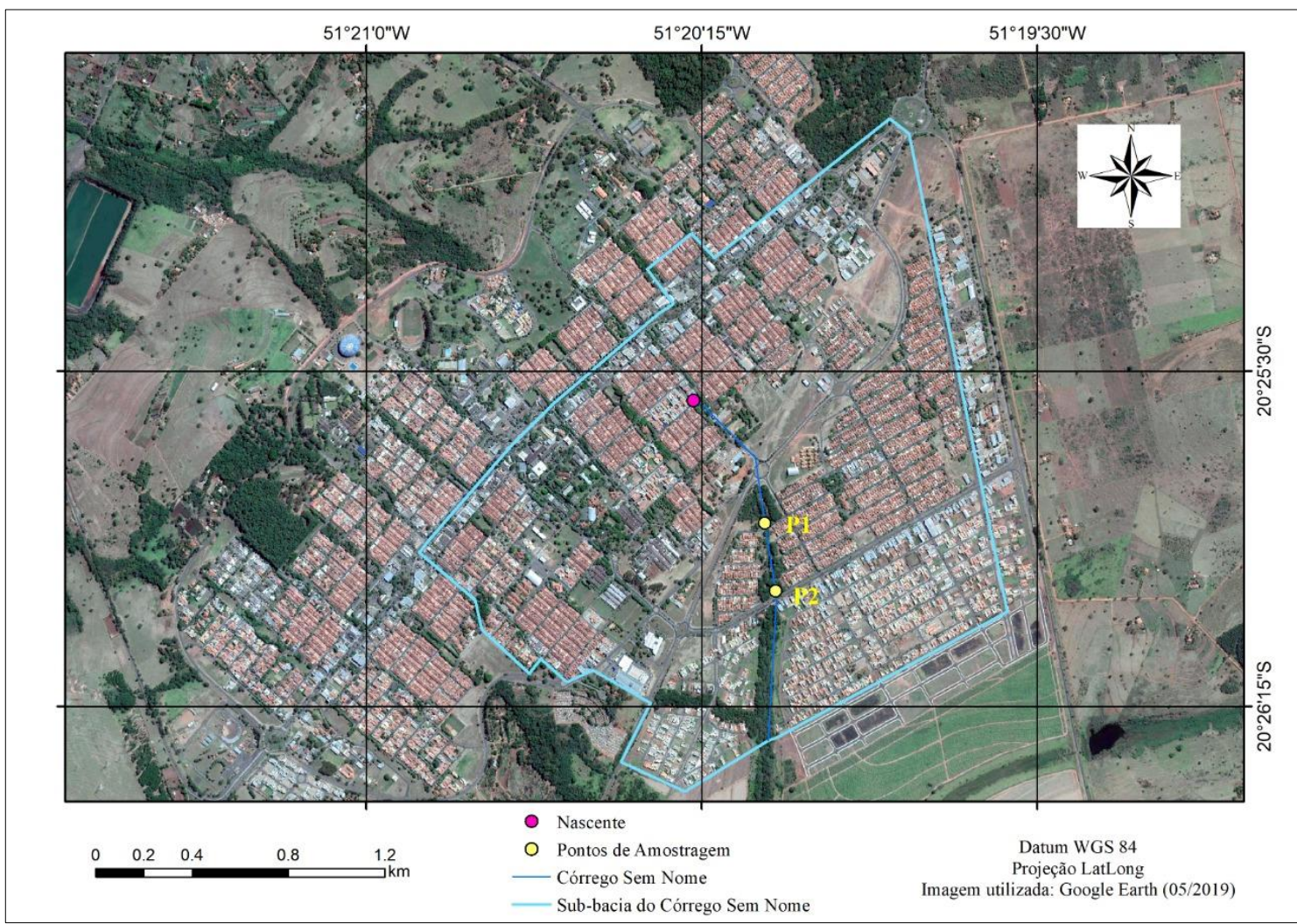

Fonte: Autores.

Os parâmetros, potencial hidrogeniônico $(\mathrm{pH})$, oxigênio dissolvido (OD), demanda bioquímica de oxigênio (DBO), fósforo total (FT) e nitrogênio total (NT), foram avaliados no Laboratório de Saneamento do Departamento de Engenharia Civil da UNESP, Câmpus de Ilha Solteira - SP, de acordo a metodologia da Standard Methods for Examination of Water and Wastewater (APHA, 2017), com os métodos utilizados para cada parâmetro químico apresentados na Tabela 2. 
Tabela 2: Métodos e equipamentos utilizados para análise da qualidade da água

\begin{tabular}{c|c|c}
\hline Parâmetro & Método & Equipamentos \\
\cline { 1 - 2 } $\mathrm{pH}$ & Eletrométrico & pHmetro Digimed DM-22 \\
\hline $\mathrm{OD}$ & Winkler modificado & Titulador \\
\hline DBO & $\begin{array}{c}\text { Winkler modificado } \\
\text { Teste de } \text { DBO }_{5,20}\end{array}$ & $\begin{array}{c}\text { COD Reactor Hach / Espectrofotômetro } \\
\text { FEMTP 600S }\end{array}$ \\
\hline FT & Colorimétrico - Digestão com persulfato & $\begin{array}{c}\text { COD Reactor Hach / Espectrofotômetro } \\
\text { Hach DR/2000 }\end{array}$ \\
\hline NT & Hach 10071 & \multicolumn{2}{c}{} \\
\hline
\end{tabular}

Fonte: Autores.

\section{3 Índices pluviométricos}

Como a precipitação que ocorre na data da coleta ou em dias anteriores influencia nos resultados encontrados, dados de chuva foram levantados. Os índices pluviométricos, necessários para a elaboração deste trabalho, foram retirados do banco de dados da Área de Hidráulica e Irrigação do Departamento de Fitossanidade, Engenharia Rural e Solos (clima.feis.unesp.br) e da estação pluviométrica do Laboratório de Hidrologia e Hidrometria, vinculados à Faculdade de Engenharia de llha Solteira - FEIS, UNESP.

\section{RESULTADOS E DISCUSSÃO}

A Tabela 3 apresenta os resultados obtidos para os parâmetros avaliados no ecossistema aquático estudado.

Tabela 3: Variação espacial dos parâmetros químicos analisados no Córrego Sem Nome

\begin{tabular}{c|c|c}
\hline \multirow{2}{*}{ Parâmetros analisados } & \multicolumn{2}{|c}{ Pontos de amostragem } \\
\cline { 2 - 3 } & P1 & P2 \\
\hline OD $\left(\mathrm{mg} . \mathrm{L}^{-1}\right)$ & 3.04 & 4.46 \\
\hline DBO $\left(\mathrm{mg} . \mathrm{L}^{-1}\right)$ & 267.56 & 11.15 \\
\hline FT $\left(\mathrm{mg} . \mathrm{L}^{-1}\right)$ & 3.35 & 0.01 \\
\hline NT $\left(\mathrm{mg} . \mathrm{L}^{-1}\right)$ & 37.00 & 3.00 \\
\hline $\mathrm{pH}$ & 7.71 & 7.91 \\
\hline
\end{tabular}

OD: oxigênio dissolvido; $\overline{\mathrm{DBO}}$ : demanda bioquímica de oxigênio; FT: fósforo total; NT: nitrogênio total; pH: potencial hidrogeniônico.

Fonte: Autores.

Esteves (2011) comenta que o pH pode ser considerado a variável ambiental mais importante em análises de recursos hídricos e que pode ser uma das mais difíceis de interpretar, devido aos inúmeros fatores que podem influenciar no seu valor. Quando apresenta uma acidez elevada, pode ser um indicador de contaminação. Já um excesso de solubilização de sais pode tornar a água impropria para o consumo humano (GLORIA, HORN e HILGEMANNA, 2017).

Os resultados obtidos para o pH são compatíveis com o intervalo recomendado para à manutenção da vida aquática em águas naturais de superfície, variando de 6,0 a 8,5, de acordo 
com Libânio (2010). Embora muito próximos, o valor encontrado para o ponto P2 foi relativamente maior que o encontrado para o ponto $\mathrm{P} 1$.

As atividades metabólicas e a saúde ecológica do ecossistema são dependentes do OD em aspectos relacionados ao papel importante que desempenha (MADER et al., 2017). Mota (2012) ressalta que o teor de OD é um forte indicador de poluição por matéria orgânica.

É possível observar que o ponto P1 apresentou a maior concentração, com uma diferença de $1,42 \mathrm{mg}$. $\mathrm{L}^{-1}$ entre as duas localidades. Isso se deve aos aspectos hidráulicos das seções do canal, assim como à presença de uma fonte de poluição. No ponto próximo à nascente, P1, encontrase um canal mais raso e com uma maior velocidade de escoamento quando comparado com o segundo ponto, P2, este apresentando um maior volume de água. A montante do ponto P1 temse o lançamento de parte da água drenada na sub-bacia.

Tanto no dia de amostragem quanto em alguns dias anteriores, houve precipitação na área de estudo (Figura 2). Por se tratar de um mês chuvoso, com precipitações que influenciam diretamente nos resultados encontrados, verifica-se que a poluição gerada na bacia de drenagem, deposição úmida e seca, não apresentou seu impacto máximo em decorrência dos inúmeros eventos ocorridos no mês, que proporcionaram a lavagem da superfície. No dia de levantamento dos dados, 28 de novembro de 2017, possivelmente, a chuva contribuiu como um fator de diluição, melhorando a qualidade desta água. Assim sendo, infere-se um possível lançamento de esgoto doméstico no ecossistema avaliado, por meio de ligações clandestinas da rede de esgoto na pluvial.

Figura 2: Histograma de chuvas diárias no mês de novembro de 2017 no município de llha Solteira - SP

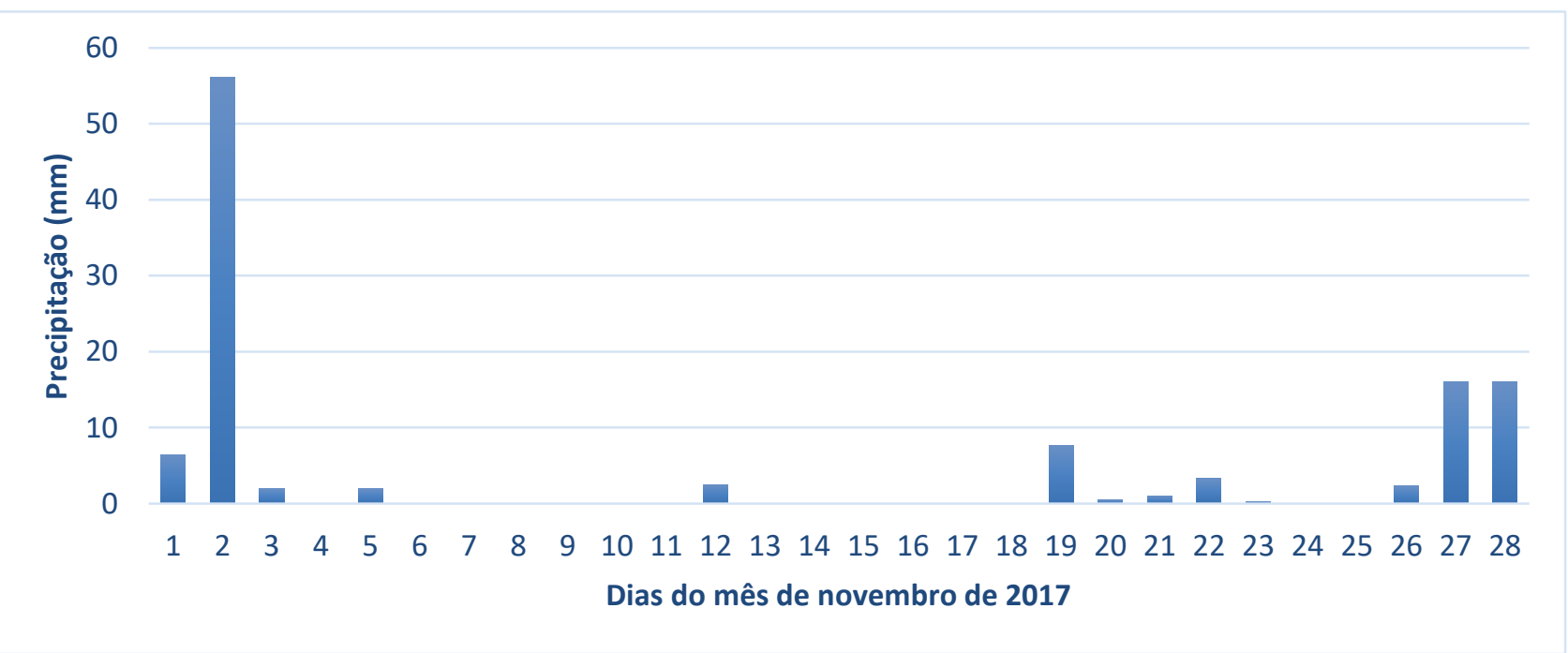

Fonte: Autores.

Definida como a quantidade de oxigênio necessária para oxidar a matéria orgânica por decomposição microbiana aeróbia, para uma forma inorgânica estável (CETESB, 2016), a DBO, assim como o OD, é considerada um indicador comum de poluição orgânica. Altos teores de DBO nos corpos d'agua representam o despejo de resíduos orgânicos no meio, o que provoca o esgotamento do OD, podendo levar a morte de espécies aquáticas. 
O teor de matéria orgânica encontrado no ponto $\mathrm{P} 1,267,56 \mathrm{mg} . \mathrm{L}^{-1}$, é extremamente preocupante, pois valores deste tipo são característicos de águas residuárias na entrada de Estações de Tratamento de Esgoto (ETE's). O mau cheiro no local sugere a existência de lançamento de esgoto in natura. Ademais, o atual estado de conservação no entorno do córrego (Figura 3) corrobora para o elevado valor verificado. Destes aspectos, com o valor obtido neste parâmetro, comenta-se, mais uma vez, a possibilidade de lançamento de esgoto clandestino.

Figura 3: Degradação no entorno do ponto P1

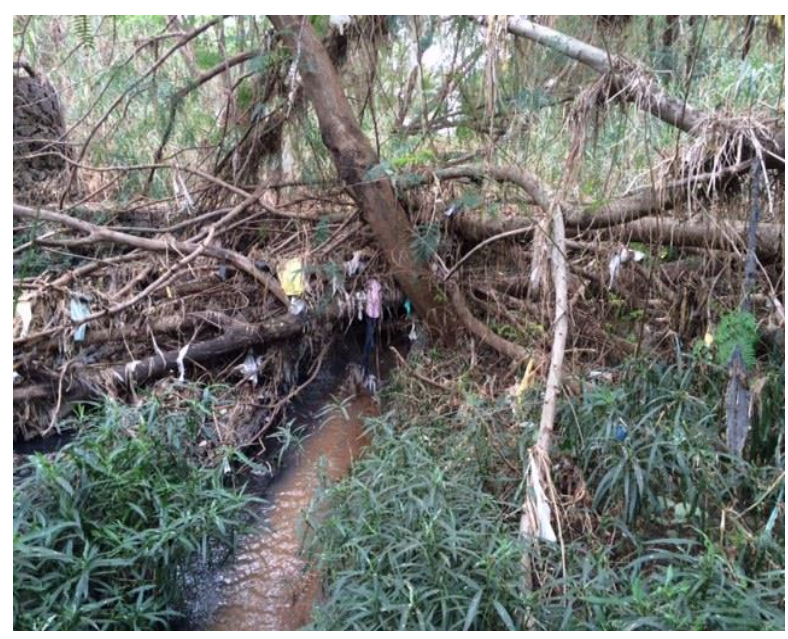

Fonte: Autores.

O FT é um dos melhores indicadores da presença de nutrientes no ecossistema aquático (VON SPERLING, 2005). Em altas concentrações, pode representar a diminuição de OD no meio e um aumento da biomassa algal em razão do processo de eutrofização, que ocorre em reservatórios e canais com escoamento lento. Em áreas urbanas, as suas diferentes formas (ortofosfato, fósforo orgânico e polifosfato) aparecem, nas águas superficiais, por meio das descargas de esgotos domésticos, matéria orgânica fecal e detergentes.

Valores característicos de concentrações deste nutriente em águas naturais que não foram submetidas ao processo de poluição variam de 0,005 a $0,020 \mathrm{mg}$. $\mathrm{L}^{-1}$ (Libânio, 2010). O ponto P2 apresentou o valor dentro deste intervalo. Todavia, verificou-se no ponto P1 uma concentração de $3,35 \mathrm{mg}$. $\mathrm{L}^{-1}$, o que infere a existência de um elevado aporte de FT.

Poleto (2003) confirmou a presença de uma ligação do pátio de veículos da Prefeitura Municipal de Ilha Solteira em um local a montante do ponto P1, responsável pelo lançamento de água de lavagem de veículos. Ademais, uma das tubulações que conduz a água de drenagem, com destino final nesse canal, fica a poucos metros do ponto $P 1$, o que justifica o alto valor encontrado, pautado na possibilidade de haver ligações clandestinas, resultando em aporte de detergentes superfosfatados e matéria orgânica fecal. De fato, encontra-se com frequência espuma nas águas desse córrego (Figura 4). 
Figura 4: Presença de espuma na água do Córrego Sem Nome

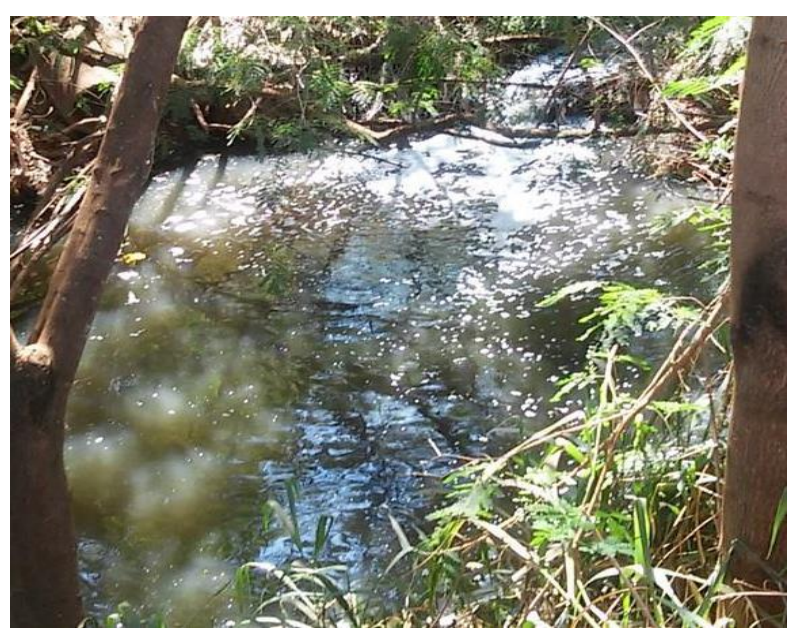

Fonte: Autores.

Assim como o FT, o NT representa uma importante fonte de nutriente para os processos biológicos. A presença de suas diferentes formas no meio aquático pode se dar por fenômenos naturais e fatores não antropogênicos, como a fixação biológica do nitrogênio atmosférico e a dissolução de outros compostos (ORTEGA, 2011). Em ambientes urbanos, o escoamento superficial, associado às deficiências do sistema de limpeza público, constitui fonte difusa de difícil caracterização desse nutriente (CETESB, 2016).

Um comportamento similar foi verificado entre os nutrientes avaliados, com concentrações mais expressivas no ponto $\mathrm{P} 1$, reforçando os fatores e aspectos levantados até o presente. Houve uma diminuição dos valores encontrados do ponto P1 para o P2. Isso se deve aos processos dispersivos, à inexistência de fontes pontuais de poluição no trecho entre as localidades e à diluição.

Da comparação com a Resolução CONAMA n 357/05 (BRASIL, 2005), realizou-se uma análise de conformidade. Verificou-se que apenas o pH atendeu ao limite estabelecido pela legislação nos dois pontos, estando entre 6,0 e 9,0. Em relação ao FT somente o P1 esteve de acordo, com um valor inferior a $0,03 \mathrm{mg} . \mathrm{L}^{-1}$. Os parâmetros OD (superior a $5,0 \mathrm{mg}$. $\mathrm{L}^{-1}$ ), DBO (inferior a 5 mg. $\mathrm{L}^{-1}$ ) e NT (especificado somente se for fator limitante para eutrofização: inferior a 1,27 $\mathrm{mg} . \mathrm{L}^{-1}$ ) apresentaram, em ambas localidades, resultados fora do permitido para um curso d'agua Classe 2.

\section{CONCLUSÕES}

Conclui-se que o Córrego Sem Nome se encontra altamente degradado, apresentando uma qualidade da água ruim, a qual pode ser usada somente para fins paisagísticos. Para tanto, os seguintes aspectos foram observados como os precursores do estado ambiental atual: falta de conservação do entrono do curso d'água; obras de drenagem deterioradas; inexistência de manutenção do canal; presença de ligações clandestinas de esgoto doméstico; e falha da população com questões voltadas à consciência ambiental. 
Vale salientar que o ponto P1 apresentou os valores mais críticos, sendo necessário uma atenção maior, visto que altas concentrações de nutrientes e elevado teor de matéria orgânica foram verificados nesse local.

\section{AGRADECIMENTO}

Ao Conselho Nacional de Desenvolvimento Científico e Tecnológico (CNPq) pela concessão da bolsa de mestrado dos autores João Miguel Merces Bega e Amanda de Moraes Ricardi, e à Coordenação de Aperfeiçoamento de Pessoal de Nível Superior (CAPES) pela concessão da bolsa de mestrado das autoras Natasha Ulhiana Ferreira Ribeiro e Juliana Cristina Ribeiro Almeida.

\section{REFERÊNCIAS BIBLIOGRÁFICAS}

American Public Health Association - APHA. Standard Methods for the Examination of Water and Wastewater, 23th ed, Washigton, DC, 2017.

ALVARES, C. A.; STAPE, J. L.; SENTELHAS, P. C.; GONÇALVES, J. L. M.; SPAROVEK, G. Köppen's climate classification map for Brazil. Meteorologische Zeitschrift, v. 22, n. 6, p. 711-728, 2013.

BAUMGARTNER, S. D.; ROBINSON, C. T. Changes in macroinvertebrate trophic structure along a landuse gradient within a lowland stream network. Aquatic Sciences, v. 79, n. 2, p. 407-418, 2017.

BRASIL - Conselho Nacional do Meio Ambiente (CONAMA). Resolução n 357/05. Estabelece a classificação das águas doces, salobras e salinas do Território Nacional. Brasília, SEMA, 2005.

BU, H.; MENG, W.; ZHANG, Y.; WAN, J. Relationships between land use patterns and water quality in the Taizi River basin, China. Ecological Indicators, v.41, p. 187-197, 2014.

CETESB (Brasil). Relatório de qualidade das águas interiores do estado de São Paulo: Apêndice E Significado ambiental e sanitário das variáveis de qualidade das águas e dos sedimentos e metodologias analíticas e de amostragem. Recurso eletrônico. São Paulo: Cetesb, 2016.

Companhia Ambiental do Estado de São Paulo - CETESB. Guia nacional de coleta e preservação de amostras: água, sedimento, comunidades aquáticas e efluentes líquidos. Organizadores: BRANDÃO, C. J.; BOTELHO, M. J. C.; SATO, M. I. Z.; LAMPARELLI, M. C. São Paulo: CETESB, Brasília: ANA, 2011, 326 p.

ESTEVES, F. A. (coord). Fundamentos de Limnologia. 3 ed. Rio de Janeiro: Interciência, 2011. 826p.

FIA, R.; TADEU, H.C.; MENEZES, J.P.C.; FIA, F.R.L.; OLIVEIRA, L.F.C. Qualidade da água de um ecossistema lótico urbano. Revista Brasileira de Recursos Hídricos, v.20(1), p. 267-275, 2015.

GLORIA, L. P.; HORN, B. C.; HILGEMANN, M. Avaliação da qualidade da água de bacias hidrográficas através da ferramenta do índice de qualidade da água - IQA. Revista Caderno Pedagógico. v. 14 (1), p. $103-119,2017$.

GUEDES, H. A. S.; SILVA, D. D.; ELESBON, A. A. A.; RIBEIRO, C. B. M.: MATOS, A. T.; SOARES, J. H. P. Aplicação da análise estatística multivariada no estudo da qualidade da água do Rio Pomba, MG. Revista Brasileira de Engenharia Agrícola e Ambiental, p. 558-563, 2012. 
IBGE - Instituto Brasileiro de Geografia e Estatística. Censo demográfico 2010: Resultados gerais da amostra. Rio de Janeiro. IBGE, 2012.

KALSCHEUR, K.N.; PENSKAR, R.R.; DALEY, A.D.; PECHAUER, S.M.; KELLY, J.J.; PETERSON, C.G. Effects of anthropogenic inputs on the organic quality of urbanized streams. Water Research, v.46, p. 2515-2524, 2012.

KANG, J.H.; LEE, S.W.; CHO, K.H.; KI, S.J.; CHA, S.M.; KIM, J.H. Linking land-use type and stream water quality using spatial data of fecal indicator bacteria and heavy metals in the Yeongsan river basin. Water Research, v.44, p. 4143-4157, 2010.

LIBÂNIO, M. Fundamentos de qualidade e tratamento de água. 3 ed. Campinas, SP: Átomo, 2010.

MADER, M.; SCHMIDT, C.; GELDERN, R.; BARTH, J. A. C. Dissolved oxygen in water and its stable isotope effects: A review. Chemical Geology, v. 473, p. 10 - 21, 2017.

MCDONALD, R. I.; GREEN, P.; BALK, D.; FEKETE, B. M.; REVENGA, C.; TODD, M.; MONTGOMERY, M. Urban growth, climate change, and freshwater availability. PNAS, v. 108, n. 15, p. 6312-6317, 2011.

MENEZES, J. P. C.; BITTENCOURT, R. P.; FARIAS, M. S.; BELLO, I. P.; FIA, R.; OLIVEIRA, L. F. C. Relação entre padrões de uso e ocupação do solo e qualidade da água em uma bacia hidrográfica urbana. Engenharia Sanitária e Ambiental, v. 21, n. 3, p. 519-534, 2016.

MOTA, S. Introdução à engenharia ambiental. 5. ed. Rio de Janeiro:ABES, 2012.

MUNYKA, S.; KONGO, V.; KIMWAGA, R. River health assessment using macroinvertebrates and water quality parameters: A case of Orange River in Namibia. Physics and Chemistry of the Earth, v. 76-77, p. 140-148, 2014.

ORTEGA, D. J. P. Avaliação dos efeitos das atividades antrópicas na bacia hidrográfica do Córrego do Ipê, município de Ilha Solteira - SP. Dissertação (Mestrado) - Faculdade de Engenharia Civil na área de recursos hídricos e tecnologias ambientais, Universidade Estadual Paulista - UNESP, Ilha Solteira, 2011. $151 \mathrm{p}$.

POLETO, C. Monitoramento e avaliação da qualidade da água de uma microbacia hidrográfica no município de Ilha Solteira - SP. Dissertação (Mestrado) - Faculdade de Engenharia Civil na área de recursos hídricos e tecnologias ambientais, Universidade Estadual Paulista - UNESP, Ilha Solteira, 2003. $161 \mathrm{p}$.

PREFEITURA MUNICIPAL DE ILHA SOLTEIRA. Ilha Solteira. 2018. Disponível em <http://www.ilhasolteira.sp.gov.br/index.php/ilha-solteira>. Acesso em 08 de maio de 2018.

RIGHETTO, A. M.; GOMES, K. M.; FREITAS, F. R. S. Poluição difusa nas águas pluviais de uma bacia de drenagem urbana. Engenharia Sanitária e Ambiental, v. 22, n. 6, p. 1109-1120, 2017.

SANTIM, T. G. S. Uso de geotecnologias na análise temporal dos impactos da urbanização na sub-bacia do Córrego Sem Nome em Ilha Solteira/SP. Dissertação (Mestrado) - Faculdade de Engenharia Civil na área de recursos hídricos e tecnologias ambientais, Universidade Estadual Paulista - UNESP, Ilha Solteira, 2010, 228 p.

SILVA, T.F.G.; LEITE, B.V.; GIANI, A.; FIGUEREDO, C.C.; PETRUCCI, G.; LEMAIRE, B.; SPERLING, E.V.; TASSIN, B.; SEIDI, M.; KHAC, V.T.; VIANA, P.S.; VIANA, V.F.V.; TOSCANO, R.A.; RODRIGUES, B.H.M.; NASCIMENTO, N.O. Modelagem da Lagoa da Pampulha: uma ferramenta para avaliar o impacto da 
bacia hidrográfica na dinâmica do fitoplâncton. Engenharia Sanitária e Ambiental, v.21(1), p. 95-108, 2016.

SRIVASTAVA, J.; GUPTA, A.; CHANDRA, H. Managing water quality with aquatic macrophytes. Revised Environmental Science Biotechnology, v.7, p. 255-266, 2008.

UNITED NATIONS. World Urbanization Prospects: The 2018 Revision. Department of Economic and Social Affairs. Population Division (Org.). New York. 2018.

VON SPERLING, M. Princípios do tratamento biológico das águas residuárias. 3. ed. Belo Horizonte: Editora UFMG, 2005.

ZAMBRANO, K. T.; POLETO, C.; OLIVEIRA, J. N. A comparative analysis on water quality in an urban watershed. Management of Environmental Quality: An International Journal, v. 28, p. 566-578, 2017. 